\title{
Blood pressure and antihypertensive medication profile in a multiethnic Asian population of stable chronic kidney disease patients
}

Boon Wee $\underline{T e}^{1}$, MBBCh, FASN, Horng Ruey $\underline{C h u a}^{2}$, MBBS, Weng Kin $\underline{\text { Wong}}^{2}$, mBBS, Sabrina $\underline{H a r o o n}^{2}$, MBBS, Srinivas Subramanian' ${ }^{2}$, MBBS, Ping Tyug $\underline{\operatorname{Loh}}^{2}$, MBBCh, Sunil Sethi ${ }^{3}$, PhD, Titus $\underline{\text { Lau }}{ }^{2}$, MD

INTRODUCTION Clinical practice guidelines recommend different blood pressure (BP) goals for chronic kidney disease (CKD) patients. Usage of antihypertensive medication and attainment of BP targets in Asian CKD patients remain unclear. This study describes the profile of antihypertensive agents used and BP components in a multiethnic Asian population with stable CKD.

METHODS Stable CKD outpatients with variability of serum creatinine levels $<20 \%$, taken $>3$ months apart, were recruited. Mean systolic blood pressure (SBP) and diastolic blood pressure (DBP) were measured using automated manometers, according to practice guidelines. Serum creatinine was assayed and the estimated glomerular filtration rate (GFR) calculated using the CKD Epidemiology Collaboration equation. BP and antihypertensive medication profile was examined using univariate analyses.

RESULTS 613 patients (55.1\% male; $74.7 \%$ Chinese, $6.4 \%$ Indian, $11.4 \%$ Malay; $35.7 \%$ diabetes mellitus) with a mean age of $57.8 \pm 14.5$ years were recruited. Mean SBP was $139 \pm 20 \mathrm{mmHg}$, DBP was $74 \pm 11 \mathrm{mmHg}$, serum creatinine was $166 \pm 115 \mu \mathrm{mol} / \mathrm{L}$ and GFR was $53 \pm 32 \mathrm{~mL} / \mathrm{min} / 1.73 \mathrm{~m}^{2}$. At a lower GFR, SBP increased $(p<0.001)$, whereas DBP decreased $(p=0.0052)$. Mean SBP increased in tandem with the number of antihypertensive agents used $(p<0.001)$, while mean DBP decreased when $\geq 3$ antihypertensive agents were used $(p=0.0020)$.

CONCLUSION Different targets are recommended for each BP component in CKD patients. A majority of patients cannot attain SBP targets and/or exceed DBP targets. Research into monitoring and treatment methods is required to better define BP targets in CKD patients.

Keywords: Asian, blood pressure, chronic renal failure, hypertension, medication

\section{INTRODUCTION}

Clinical practice guidelines vary in their recommended blood pressure (BP) targets for patients with chronic kidney disease (CKD). ${ }^{(1-4)}$ Guidelines in a report by the Eighth Joint National Committee recommend a conservative goal of $<140 / 90 \mathrm{mmHg}$, with an emphasis on adjusting goals depending on age and comorbidities. ${ }^{(4)}$ United States National Kidney Foundation (US NKF) guidelines, however, recommend a target BP of $<130 / 80 \mathrm{mmHg}$ for CKD patients, with a further goal of $<125 / 75 \mathrm{mmHg}$ for patients with proteinuria $>1 \mathrm{~g} /$ day, especially if diabetes mellitus is the cause of CKD. ${ }^{(1,2)}$ Many patients with CKD require multiple antihypertensive agents to attain control. ${ }^{(5)}$ It has also been noted that, in practice, many patients given treatment and medical attention are unable to attain BP goals in outpatient clinics, even in the clinical trial setting. ${ }^{(5,6)}$ As clinical practice guidelines provide varying recommendations for different categories of patients, the stated BP targets are controversial. ${ }^{(5,7,8)}$ Additionally, some have argued that the lower BP targets recommended for CKD patients are an extrapolation from pre-existing studies and not supported by strong clinical trial evidence. ${ }^{(1,2,9)}$ Nonetheless, the US NKF guidelines have been very influential in nephrology practices, and many CKD programmes aim to achieve the lower general target of $<130 / 80 \mathrm{mmHg}$.

Regardless of practice guidelines, individual physicians differ in their preferences, beliefs, practices and patient types. In light of this controversy, this study examined the profile of BP components and antihypertensive agent usage in a multiethnic Asian population with stable CKD. The target population was patients in an academic, nephrology, tertiary referral practice in Singapore; to the best of our knowledge, the profile of such a population is still unclear.

\section{METHODS}

Data was taken from a cross-sectional observational study on serum cardiac biomarkers in CKD patients (NKFRC/2011/07/21). Outpatients with stable CKD at National University Hospital, Singapore, were prospectively recruited. Stable CKD patients were defined as those with variability of serum creatinine levels $<20 \%$ (taken more than three months apart) and who were diagnosed with CKD as defined by the US NKF guidelines. ${ }^{(10)}$ At our institution, patients identified as having CKD had the following characteristics for more than three months: estimated glomerular filtration rate $(\mathrm{GFR})<60 \mathrm{~mL} / \mathrm{min} / 1.73 \mathrm{~m}^{2}$; better GFR,

${ }^{1}$ Department of Medicine, Yong Loo Lin School of Medicine, National University of Singapore, ${ }^{2}$ Department of Medicine, National University Health System, ${ }^{3}$ Department of Pathology, Yong Loo Lin School of Medicine, National University of Singapore, Singapore

Correspondence: Dr Boon Wee Teo, Associate Professor, Department of Medicine, Yong Loo Lin School of Medicine, National University of Singapore, 1 E Kent Ridge Road, Level 10 NUHS Tower Block, Singapore 119228. mdctbw@nus.edu.sg 
but with evidence of urinary abnormalities; or abnormalities of the kidneys on imaging. All patients with available BP readings were included. Mean systolic blood pressure (SBP) and diastolic blood pressure (DBP) levels were measured using automated manometers (DINAMAP; GE Healthcare, Singapore) according to clinical practice guidelines, with an average of at least two readings per patient.

Standardised serum creatinine was assayed and GFR calculated using the CKD Epidemiology Collaboration equation. ${ }^{(11)}$ The study population was classified by CKD stages according to their GFR. Data was presented as mean \pm standard deviation, median (25th-75th percentile) or frequency (percentage), where appropriate. BP and antihypertensive medication profile was examined using univariate analyses via standard statistical tests. A p-value $<0.05$ indicated statistical significance.

\section{RESULTS}

A total of 613 patients were included; the majority were male $(55.1 \%)$ and of Chinese ethnicity $(74.7 \%)$, with a mean age of $57.8 \pm 14.5$ years (Table I). $35.7 \%$ of patients had a history of diabetes mellitus and $69.0 \%$ were previously diagnosed with hypertension.

The mean SBP was $139 \pm 20 \mathrm{mmHg}$, DBP was $74 \pm 11 \mathrm{mmHg}$, serum creatinine was $166 \pm 115 \mu \mathrm{mol} / \mathrm{L}$ and GFR was $53 \pm 32 \mathrm{~mL} / \mathrm{min} / 1.73 \mathrm{~m}^{2}$. With increasing age, SBP increased (108.9 $+0.51 \times$ age, $p<0.001)$, but DBP decreased (83.6 - $0.16 \times$ age, $\mathrm{p}<0.001$ ) (Fig. 1). Mean DBP was lower in women than in men (72 $\pm 10 \mathrm{mmHg}$ vs. $76 \pm 11 \mathrm{mmHg}, \mathrm{p}<0.0010$ ) (Table II). SBP increased $(146.5-0.15 \times$ GFR, $p<0.001)$ and DBP decreased $(72.2+0.04 \times$ GFR, $p=0.0052)$ with lower GFR (Fig. 2). Mean SBP increased in tandem with the number of antihypertensive agents used $(p<0.001)$, whereas mean DBP decreased when $\geq 3$ antihypertensive agents were used $(p=0.0020)$ (Table II).

Patients with diabetes mellitus had a higher mean SBP (144 $\pm 21 \mathrm{mmHg}$ vs. $136 \pm 20 \mathrm{mmHg} ; \mathrm{p}<0.001)$ and DBP (76 $\pm 11 \mathrm{mmHg}$ vs. $72 \pm 11 \mathrm{mmHg} ; \mathrm{p}<0.001)$ compared to those who did not. Patients with a prior diagnosis of hypertension had a higher mean SBP $(142 \pm 20 \mathrm{mmHg}$ vs. $131 \pm 19$ mmHg; $p<0.001)$ but similar mean DBP compared to those who were not diagnosed with hypertension. Patients diagnosed with coronary artery disease had a higher mean SBP $(137 \pm 20 \mathrm{mmHg}$ vs. $133 \pm 20 \mathrm{mmHg} ; \mathrm{p}=0.0027)$ but a lower mean DBP $(72 \pm 11 \mathrm{mmHg}$ vs. $75 \pm 11 \mathrm{mmHg} ; \mathrm{p}=0.0023)$ compared to those who did not have the diagnosis. The SBP of the 191 patients aged $>65$ years was proportionately lower than that of younger patients as SBP thresholds decreased; the converse was observed for DBP (Table III). In patients aged $\leq 65$ years, the number of antihypertensive agents used was associated with attaining the SBP target of $<140 \mathrm{mmHg}$ $(p=0.0484)$. A total of 150 (24.5\%) out of 613 patients achieved both targets of SBP $<140 \mathrm{mmHg}$ and DBP $<70 \mathrm{mmHg} ; 26.2 \%$ $(50 / 191)$ of the patients who were aged $>65$ years and $23.7 \%$ (100/422) of those aged $\leq 65$ years attained these targets.

A total of 1,136 antihypertensive agents from 11 types of medications were prescribed. Renin-angiotensin-aldosterone
Table I. Demographic and clinical characteristics of the study population $(n=613)$.

\begin{tabular}{|c|c|}
\hline Parameter & No. (\%) \\
\hline Age* $^{*}(y r)$ & $57.8 \pm 14.5$ \\
\hline \multicolumn{2}{|l|}{ Gender } \\
\hline Male & $338(55.1)$ \\
\hline Female & $275(44.9)$ \\
\hline \multicolumn{2}{|l|}{ Ethnicity } \\
\hline Chinese & $458(74.7)$ \\
\hline Malay & $70(11.4)$ \\
\hline Indian & $39(6.4)$ \\
\hline Others & $46(7.5)$ \\
\hline Current smoker & $40(6.5)$ \\
\hline \multicolumn{2}{|l|}{ Cause of chronic kidney disease } \\
\hline Diabetes mellitus & $204(33.3)$ \\
\hline Glomerular disease & $138(22.5)$ \\
\hline Hypertension & $113(18.4)$ \\
\hline Presumed chronic glomerular disease & $61(10.0)$ \\
\hline Polycystic kidney disease & $24(3.9)$ \\
\hline Kidney transplant & $21(3.4)$ \\
\hline Solitary kidney & $16(2.6)$ \\
\hline Obstructive uropathy & $5(0.8)$ \\
\hline Others & $31(5.1)$ \\
\hline \multicolumn{2}{|l|}{ Medical history ${ }^{+}$} \\
\hline Hypertension & $423(69.0)$ \\
\hline Diabetes mellitus & $219(35.7)$ \\
\hline Coronary artery disease & $106(17.3)$ \\
\hline Cerebrovascular disease & $49(8.0)$ \\
\hline Chronic obstructive pulmonary disease & $7(1.1)$ \\
\hline Peripheral arterial disease & $26(4.2)$ \\
\hline Kidney stones & $64(10.4)$ \\
\hline Height* $^{*}(\mathrm{~cm})$ & $161 \pm 10$ \\
\hline Weight* (kg) & $69.2 \pm 15.7$ \\
\hline Body mass index* $\left(\mathrm{kg} / \mathrm{m}^{2}\right)$ & $26.6 \pm 5.4$ \\
\hline Systolic blood pressure* $(\mathrm{mmHg})$ & $139 \pm 20$ \\
\hline Diastolic blood pressure* $(\mathrm{mmHg})$ & $74 \pm 11$ \\
\hline Pulse rate* (bpm) & $70 \pm 12$ \\
\hline Serum creatinine ${ }^{*}(\mu \mathrm{mol} / \mathrm{L})$ & $129(87-204)$ \\
\hline $\mathrm{GFR}^{*}\left(\mathrm{~mL} / \mathrm{min} / 1.73 \mathrm{~m}^{2}\right)$ & $45(26-77)$ \\
\hline
\end{tabular}

* Data presented as mean \pm standard deviation. + Some patients had a history of more than one condition. \#Data presented as median (25th-75th percentile). bpm: beats per minute; GFR: estimated glomerular filtration rate

system (RAAS) blockers were the most commonly prescribed antihypertensive agents (34.4\%, $\mathrm{n}=391)$, with 35 patients on both an angiotensin-converting enzyme inhibitor (ACE-I) and angiotensin receptor blocker (ARB). The distribution of antihypertensive agents used is shown in Fig. 3. A greater proportion of patients with a history of diabetes mellitus were on an ACE-I or ARB (153/219, $69.9 \%$ ) compared to non-diabetics (238/394, 60.4\%; $p=0.0225)$; similarly, more patients diagnosed with diabetic CKD were on an ACE-I or ARB (142/204, 69.6\%) compared to those without diabetic CKD (249/409, 60.9\%; $p=0.0401)$. Additionally, a greater proportion of patients with a history of coronary artery disease were on beta-blockers (48/106, 45.3\%) compared to those without a history of coronary artery disease $(72 / 507,14.2 \%$; $p<0.001)$; the 

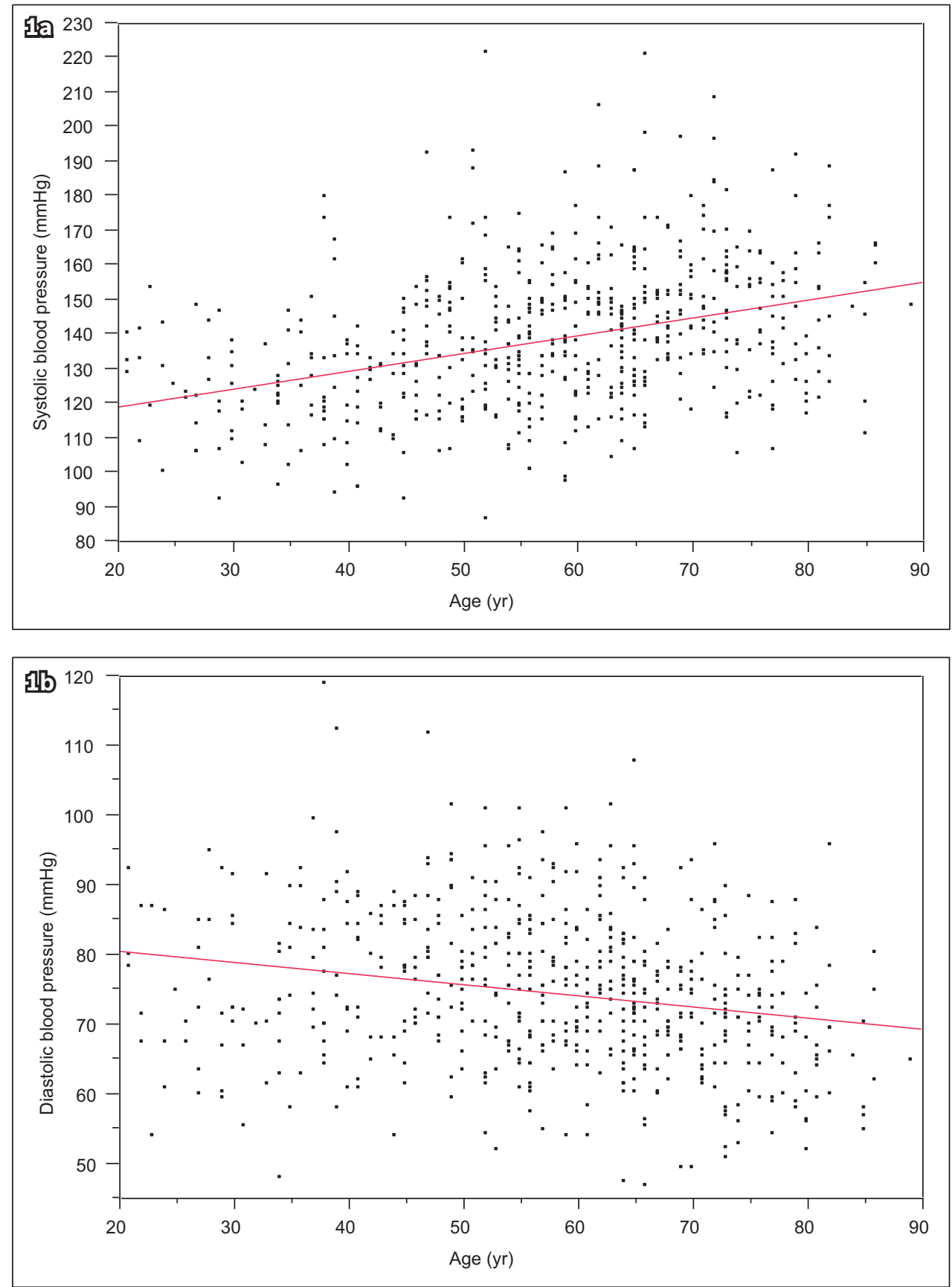

Fig. 1 Scatter graphs show mean (a) systolic and (b) diastolic blood pressure, by age.

Table II. Mean blood pressure, by number of antihypertensive agents used and gender.

\begin{tabular}{|c|c|c|c|c|c|c|c|c|c|c|c|}
\hline \multirow[t]{2}{*}{ No. } & \multicolumn{3}{|c|}{ All $(n=613)$} & \multicolumn{3}{|c|}{ Male $(n=338)$} & \multicolumn{3}{|c|}{ Female $(n=275)$} & \multicolumn{2}{|c|}{ p-value } \\
\hline & $\mathbf{n}$ & $\begin{array}{c}\text { SBP } \\
(\mathrm{mmHg})\end{array}$ & $\begin{array}{c}\text { DBP } \\
(\mathrm{mmHg})\end{array}$ & $\mathbf{n}$ & $\begin{array}{c}\text { SBP } \\
(\mathrm{mmHg})\end{array}$ & $\begin{array}{c}\text { DBP } \\
(\mathrm{mmHg})\end{array}$ & $\mathbf{n}$ & $\begin{array}{c}\text { SBP } \\
(\mathrm{mmHg})\end{array}$ & $\begin{array}{c}\text { DBP } \\
(\mathrm{mmHg})\end{array}$ & SBP & DBP \\
\hline 0 & 106 & $133 \pm 19$ & $75 \pm 11$ & 46 & $135 \pm 17$ & $80 \pm 11$ & 60 & $132 \pm 21$ & $71 \pm 10$ & 0.506 & $<0.001$ \\
\hline 1 & 163 & $135 \pm 20$ & $75 \pm 10$ & 82 & $135 \pm 19$ & $77 \pm 11$ & 81 & $136 \pm 20$ & $73 \pm 9$ & 0.823 & 0.015 \\
\hline 2 & 161 & $140 \pm 20$ & $76 \pm 11$ & 101 & $139 \pm 22$ & $77 \pm 11$ & 60 & $142 \pm 25$ & $74 \pm 10$ & 0.432 & 0.069 \\
\hline$\geq 3$ & 183 & $143 \pm 21$ & $72 \pm 11$ & 109 & $142 \pm 22$ & $73 \pm 10$ & 74 & $145 \pm 20$ & $70 \pm 12$ & 0.571 & 0.057 \\
\hline
\end{tabular}

DBP: diastolic blood pressure; SBP: systolic blood pressure

former group achieved a lower average pulse rate $(68 \pm 11 \mathrm{bpm}$ vs. $71 \pm 12$ bpm; $p=0.0132$ ).

At higher CKD stages, more patients were on diuretics, beta-blockers or dihydropyridine calcium channel blockers
(CCB) (Table IV). However, a significantly smaller proportion of patients with Stage 5 CKD were on RAAS blockers. Compared to patients aged $\leq 65$ years, more patients aged $>65$ years were on a diuretic $(124 / 422,29.4 \%$ vs. $87 / 191,45.5 \%$; p < 0.001 ) 

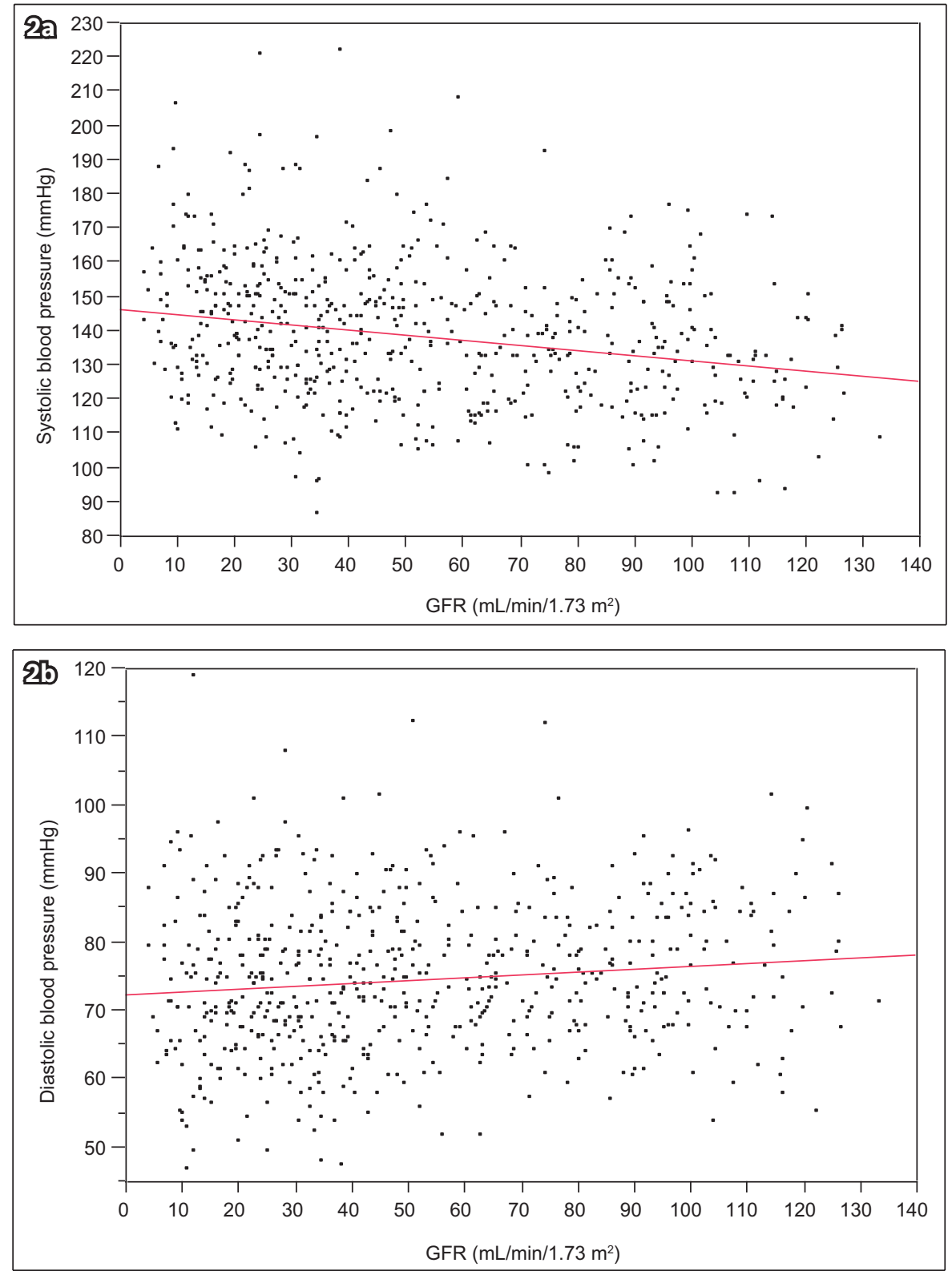

Fig. 2 Scatter graphs show mean (a) systolic and (b) diastolic blood pressure, by estimated glomerular filtration rate (GFR).

Table III. Proportion of patients who attained blood pressure thresholds.

\begin{tabular}{|c|c|c|c|}
\hline \multirow[t]{2}{*}{ Threshold } & \multicolumn{2}{|c|}{ No. (\%) } & \multirow[t]{2}{*}{ p-value* } \\
\hline & $\leq 65 \mathrm{yr}(\mathrm{n}=422)$ & $>65 \mathrm{yr}(\mathrm{n}=191)$ & \\
\hline \multicolumn{4}{|c|}{ SBP (mmHg) } \\
\hline$<140$ & $262(62.1)$ & $70(36.6)$ & $<0.001$ \\
\hline$<130$ & 175 (41.5) & $34(17.8)$ & $<0.001$ \\
\hline$<125$ & $138(32.7)$ & $23(12.0)$ & $<0.001$ \\
\hline$<100$ & $10(2.4)$ & 0 & 0.006 \\
\hline \multicolumn{4}{|c|}{ DBP (mmHg) } \\
\hline$<90$ & $373(88.4)$ & $186(97.4)$ & $<0.001$ \\
\hline$<80$ & 269 (63.7) & 165 (86.4) & $<0.001$ \\
\hline$<75$ & $192(45.5)$ & $138(72.3)$ & $<0.001$ \\
\hline$<60$ & $17(4.0)$ & $29(15.2)$ & $<0.001$ \\
\hline
\end{tabular}

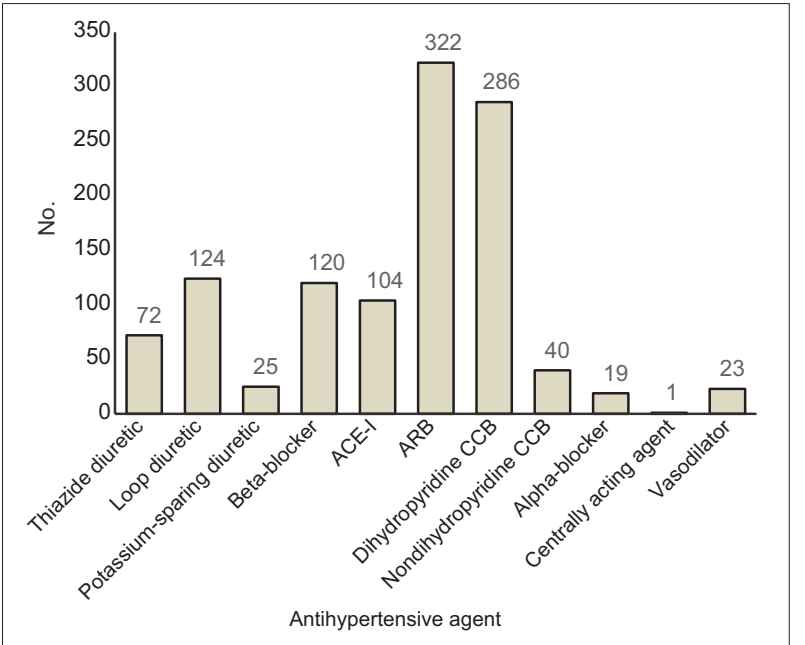

Fig. 3 Chart shows distribution of antihypertensive agents used. ACE-I: angiotensin-converting enzyme inhibitor; ARB: angiotensin-receptor blocker; CCB: calcium channel blocker 
Table IV. Distribution of antihypertensive agents used, by chronic kidney disease (CKD) stage.

\begin{tabular}{|c|c|c|c|c|c|c|c|}
\hline \multirow[t]{2}{*}{ Antihypertensive agent } & \multicolumn{6}{|c|}{ CKD stage (\%) } & \multirow[t]{2}{*}{ p-value* } \\
\hline & $1(n=129)$ & $2(n=116)$ & $3 a(n=76)$ & $3 b(n=111)$ & $4(n=122)$ & $5(n=59)$ & \\
\hline Diuretic & 14.0 & 17.2 & 17.1 & 39.6 & 61.5 & 69.5 & $<0.001$ \\
\hline Beta-blocker & 6.2 & 10.3 & 29.0 & 23.4 & 26.2 & 33.9 & $<0.001$ \\
\hline ACE-I or ARB & 48.8 & 57.8 & 75.0 & 71.2 & 77.9 & 50.9 & $<0.001$ \\
\hline Dihydropyridine CCB & 17.1 & 33.6 & 46.1 & 56.8 & 68.9 & 72.9 & $<0.001$ \\
\hline Alpha-blocker & 0.8 & 1.7 & 2.6 & 1.8 & 6.6 & 6.8 & - \\
\hline Centrally acting agent & 0 & 0 & 0 & 0 & 0 & 1.7 & - \\
\hline Vasodilator & 1.6 & 2.6 & 1.3 & 1.8 & 5.7 & 13.6 & - \\
\hline
\end{tabular}

Some patients used $\geq 2$ medications from the same class/type. *Obtained by chi-square test and omitted for medication classes where data was inadequate for valid results. ACE-I: angiotensin-converting enzyme inhibitor; ARB: angiotensin receptor blocker; CCB: calcium channel blocker

and on $\geq 3$ antihypertensive agents $(22.5 \%$ vs. $46.1 \%)$. They were also more likely to be on a beta-blocker (19.6\% vs. $14.2 \%$; $\mathrm{p}<0.001)$, dihydropyridine CCB $(67.5 \%$ vs. $37.2 \%, p<0.001)$ and alpha-blocker $(6.8 \%$ vs. $1.4 \% ; p<0.001)$. Usage of ACE-I/ ARB and nondihydropyridine CCBs was not significantly different by age group.

The most commonly prescribed medications were: losartan (178/426, 41.8\%), an RAAS blocker; atenolol (54/120, 45.0\%), a beta-blocker; amlodipine (187/326,57.4\%), a dihydropyridine CCB; furosemide $(122 / 221,55.2 \%)$, a diuretic; and prazosin $(10 / 19,52.6 \%)$, an alpha-blocker. Only one patient was on the central agent methyldopa, 23 patients were on the vasodilator hydralazine, and 15 patients were on both dihydropyridine and nondihydropyridine CCBs.

\section{DISCUSSION}

The most important therapeutic step in the general retardation of CKD progression is the management of BP to within target levels. However, different clinical practice guidelines recommend varying therapy targets. ${ }^{(1-4)}$ Using an initial SBP target of $<140 \mathrm{mmHg}$, the present study on stable CKD patients found that only $62.1 \%$ of patients aged $\leq 65$ years and considerably fewer older patients (36.6\%) achieved the target, although the study population underwent regular outpatient nephrology clinic follow-up. The overall attainment was similar to that of a large US cohort study. ${ }^{(6)}$

It was unsurprising that a large proportion of younger patients did not achieve the SBP target despite being on followup. ${ }^{(5)}$ This may have been due to an inadequate number, type and dose of antihypertensive agents. Another possibility is that younger patients with better kidney function did not undergo dietary sodium restriction and diuretic therapy. ${ }^{(12)}$ SBP targets are harder to attain in older participants, in whom widening of pulse pressure may occur after DBP levels are lowered in the course of treatment. ${ }^{(13)}$ Studies have shown that excessively low DBP may be associated with increased morbidity and mortality; therefore, it is important to consider BP targets for individual patients in association with age, comorbid conditions and risk of falls. ${ }^{(6,14)}$ In our cohort, more than a quarter of the elderly patients (age $>65$ years) had SBP $<140 \mathrm{mmHg}$ and DBP $<70 \mathrm{mmHg}$, which are associated with an increased risk of mortality in
CKD patients. ${ }^{(6)}$ Since the general aim was to reduce the risk of CKD progression and mortality, it is important to note that widened pulse pressures are also associated with end-stage renal disease. ${ }^{(15)}$ In younger patients, it can be argued that more aggressive goals and treatments can be entertained to avoid end-stage kidney failure and a lifetime of dialysis. Moreover, more intensive BP control is not necessarily associated with increased morbidity. ${ }^{(16)}$ Further randomised controlled trials are needed to clarify treatment targets for each component of BP in CKD patients. ${ }^{(5)}$

Another issue with the use of BP targets is the monitoring of $B P .{ }^{(17)}$ In the outpatient clinic, BP readings are often inaccurate for a variety of reasons, and hence data collected outside a clinical trial setting may contain relatively higher readings, ${ }^{(17)}$ compounding the mortality risk. BP readings may be lower given adequate time and equipment, as well as appropriate personnel training and the assignment of the best person to the task. ${ }^{(18)}$ At our institution, there was a risk of obtaining incorrect blood pressure readings despite the presence of dedicated and trained research personnel using regularly calibrated automated manometers for measuring BP. ${ }^{(18)}$ However, taking the average of several BP readings from a relatively large cohort reduced the risk of inaccuracy. Moreover, data collected in this study was similar to that observed in other CKD cohorts. ${ }^{(13,15)}$ Some would argue that adding 24-hour ambulatory BP monitoring may help to identify at-risk individuals and further improve the management of BP targets. ${ }^{(19)}$ However, it was also noted that most of the major clinical trials on hypertension only used ambulatory (office-based) $\mathrm{BP}^{(19)}$ and, for reasons of cost and convenience, nephrology clinics and practice groups in Singapore currently use office-based BP levels for management, except in cases of clinical uncertainty (masked or 'white-coat' hypertension).

The type of antihypertensive agent prescribed is typically dictated by indications for its use and physician preferences. RAAS blockers are widely used in earlier stages of CKD, but their usage falls significantly at Stage 5 CKD, presumably due to the potential problem of hyperkalaemia and concerns that an excessive reduction in GFR may contribute to it. Conversely, diuretic usage increases from Stage 4 to Stage 5 CKD, in keeping with the likelihood that more severe fluid overload or oedema with progressive kidney disease requires therapy intensification. 
Dihydropyridine CCB usage is relatively similar at all stages of CKD. Overall, proportionately more antihypertensive agents are used at Stage 5 CKD.

The specific medications used in our institution are, typically, dictated primarily by indications and partly by available formulary, as a result of open market tenders. Generally, medications for which generic versions are available are prescribed more frequently. The most commonly used ARB is losartan, followed by irbesartan, telmisartan and valsartan. The most frequently prescribed ACE-I is enalapril, followed by lisinopril, perindopril and ramipril. As many patients with CKD also have coronary artery disease and ischaemic heart disease complicated by left heart failure, carvedilol and bisoprolol are often also prescribed. The most frequently prescribed beta-blocker was atenolol. However, it has been reported that metoprolol may be preferable, especially in cases of more advanced kidney failure, as atenolol is cleared by the kidneys and may be associated with heart block. ${ }^{(20)}$ This may not necessarily improve mortality; another retrospective cohort study showed that elderly patients (> 75 years) who were prescribed atenolol had a reduced risk of mortality compared to patients prescribed metoprolol tartrate, yet had similar risks of hypotension and bradycardia. ${ }^{(21)}$ Amlodipine is the most commonly used dihydropyridine CCB to a considerable extent, followed by nifedipine. For nondihydropyridine CCBs, typically prescribed for additional blood pressure control and as an adjunct to reduce proteinuria, ${ }^{(1,22,23)}$ more patients were on diltiazem than verapamil. The risk of or known coronary artery disease in patients usually precludes the use of verapamil, as it is associated with heart block when beta-blockers are concomitantly administered. Even though medications in the same antihypertensive class have similar mechanisms of action, the medications may have demonstrable differences in their ability to reduce morbidity and mortality. ${ }^{(24-26)}$ Large practice data analyses would be helpful in future to examine potential advantages of certain types of medications. ${ }^{(25)}$

The present study had its limitations. As it was a crosssectional descriptive study, there was a lack of outcome data on patient mortality and morbidity. Elderly patients who declined or were excluded from participation due to their inability to provide consent or venepuncture might have different BP levels and medications from those found in the study. Some patients may have been seen by medical providers in other institutions and had incomplete medication information, particularly less educated patients who were not able to describe their entire medication list. Another major limiting factor was the lack of standardised data on the degree of albuminuria in patients, which may have impacted the aggressiveness of the prescribing physician's treatment targets and antihypertensive prescriptions. No urine samples were collected previously because the data was originally for a serum biomarker study. In our institution, urine protein-to-creatinine ratio, albumin-to-creatinine ratio or 24-hour urine collections are ordered at the attending physician's discretion; therefore, collected data is not standardised in format and chronology. Nevertheless, the majority of patients on followup at the kidney disease clinics usually have clinically significant proteinuria $>0.5 \mathrm{~g} /$ day, as the institution is a tertiary referral centre. The strengths of our study were its prospective nature and the fairly large study sample of multiethnic Asian patients with stable CKD. With this sample, a cross-sectional examination could be conducted on BP levels attained for each BP component, following therapy principally guided by nephrologists.

In summary, many of our patients failed to attain the target BP, but a significant proportion of them may be considered higher risk if their SBP and DBP are taken into account. An increase in the number of antihypertensive agents used resulted in divergence in the achievement of targets. Further research to improve methods of monitoring and treatment is required to better achieve targets, and link BP parameters to GFR decline and mortality in Asian CKD patients.

\section{ACKNOWLEDGEMENTS}

The project was funded by a National Kidney Foundation, Singapore, research grant awarded to Dr Boon Wee Teo (NKFRC/2011/07/21). Mr Qi Chun Toh, Mr Zichao Chen and Ms Hwee Min Loh from the National University Health System, Singapore, recruited the participants, collected the data and prepared the database. We acknowledge the study investigators, Dr Martin Lee, Prof Evan Lee and Prof Vathsala of the National University Health System Nephrology Clinical Research Group, Singapore, who actively recruited participants for this study.

\section{REFERENCES}

1. Kidney Diseases Outcomes Quality Initiative (K/DOQI). K/DOQI clinical practice guidelines on hypertension and antihypertensive agents in chronic kidney disease. Am J Kidney Dis 2004; 43(5 Suppl 1):S1-290.

2. KDOQI. KDOQI Clinical Practice Guidelines and Clinical Practice Recommendations for Diabetes and Chronic Kidney Disease. Am J Kidney Dis 2007; 49(2 Suppl 2):S12-154.

3. Chobanian AV, Bakris GL, Black HR, et al; National Heart, Lung, and Blood Institute Joint National Committee on Prevention, Detection, Evaluation, and Treatment of High Blood Pressure; National High Blood Pressure Education Program Coordinating Committee. The Seventh Report of the Joint National Committee on Prevention, Detection, Evaluation, and Treatment of High Blood Pressure: the JNC 7 report. JAMA 2003; 289:2560-72.

4. James PA, Oparil S, Carter BL, et al. 2014 evidence-based guideline for the management of high blood pressure in adults: report from the panel members appointed to the Eighth Joint National Committee (JNC 8). JAMA 2014; 311:507-20.

5. Sarafidis PA, Ruilope LM. Aggressive blood pressure reduction and renin-angiotensin system blockade in chronic kidney disease: time for re-evaluation? Kidney Int 2014; 85:536-46.

6. Kovesdy CP, Bleyer AJ, Molnar MZ, et al. Blood pressure and mortality in U.S. veterans with chronic kidney disease: a cohort study. Ann Intern Med 2013; 159:233-42.

7. Phoon IK. Are we any clearer on the blood pressure targets? Singapore Med J 2014; 55:553.

8. Schneider MP, Hilgers KF. What should be the goal blood pressure in nondiabetic chronic kidney disease? Curr Opin Nephrol Hypertens 2014; 23:180-5.

9. How $\mathrm{CH}$, Quah HM. Authors' reply: Are we any clearer on the blood pressure targets? Singapore Med J 2014; 55:554.

10. National Kidney Foundation. K/DOQI clinical practice guidelines for chronic kidney disease: evaluation, classification, and stratification. Am J Kidney Dis 2002; 39(2 Suppl 1):S1-266.

11. Levey AS, Stevens LA, Schmid CH, et al; CKD-EPI (Chronic Kidney Disease Epidemiology Collaboration). A new equation to estimate glomerular filtration rate. Ann Intern Med 2009; 150:604-12

12. Teo BW, Bagchi S, Xu H, et al. Dietary sodium intake in a multiethnic Asian population of healthy participants and chronic kidney disease patients. Singapore Med J 2014; 55:652-5. 
13. Peralta CA, Shlipak MG, Wassel-Fyr C, et al. Association of antihypertensive therapy and diastolic hypotension in chronic kidney disease. Hypertension 2007; 50:474-80.

14. Kovesdy CP, Trivedi BK, Kalantar-Zadeh K, Anderson JE. Association of low blood pressure with increased mortality in patients with moderate to severe chronic kidney disease. Nephrol Dial Transplant 2006; 21:1257-62.

15. Peralta CA, Norris KC, Li S, et al; KEEP Investigators. Blood pressure components and end-stage renal disease in persons with chronic kidney disease: the Kidney Early Evaluation Program (KEEP). Arch Intern Med 2012; 172:41-7.

16. Margolis KL, Palermo L, Vittinghoff E, et al. Intensive blood pressure control, falls, and fractures in patients with type 2 diabetes: the ACCORD trial. J Gen Intern Med 2014; 29:1599-606.

17. Appel LJ, Miller ER 3rd, Charleston J. Improving the measurement of blood pressure: is it time for regulated standards? Ann Intern Med 2011; 154:838-40.

18. Vidt DG, Lang RS, Seballos RJ, et al. Taking blood pressure: too important to trust to humans? Cleve Clin J Med 2010; 77:683-8.

19. Minutolo R, Gabbai FB, Agarwal R, et al. Assessment of achieved clinic and ambulatory blood pressure recordings and outcomes during treatment in hypertensive patients with CKD: a multicenter prospective cohort study.
Am J Kidney Dis 2014; 64:744-52.

20. Furgeson SB, Chonchol M. Beta-blockade in chronic dialysis patients. Semin Dial 2008; 21:43-8.

21. Fleet JL, Weir MA, McArthur E, et al. Kidney function and populationbased outcomes of initiating oral atenolol versus metoprolol tartrate in older adults. Am J Kidney Dis 2014; 64:883-91.

22. Demarie BK, Bakris GL. Effects of different calcium antagonists on proteinuria associated with diabetes mellitus. Ann Intern Med 1990; 113:987-8.

23. Ruggenenti $P$, Perticucci $E$, Cravedi $P$, et al. Role of remission clinics in the longitudinal treatment of CKD. J Am Soc Nephrol 2008; 19:1213-24.

24. Tomiyama $H$, Yamashina A. Beta-Blockers in the Management of Hypertension and/or Chronic Kidney Disease. Int J Hypertens 2014; 2014:919256.

25. Pilote L, Abrahamowicz M, Rodrigues E, Eisenberg MJ, Rahme E. Mortality rates in elderly patients who take different angiotensin-converting enzyme inhibitors after acute myocardial infarction: a class effect? Ann Intern Med 2004; 141:102-12.

26. Ptinopoulou AG, Pikilidou MI, Lasaridis AN. The effect of antihypertensive drugs on chronic kidney disease: a comprehensive review. Hypertens Res 2013; 36:91-101. 